\title{
Cause of death in patients with rheumatoid arthritis with particular reference to azathioprine
}

\author{
P. LEWIS, ${ }^{1}$ B. L. HAZLEMAN, ${ }^{1}$ R. HANKA, ${ }^{2}$ AND SARAH ROBERTS ${ }^{2}$
}

From the ${ }^{1}$ Rheumatology Department, Addenbrooke's Hospital, Cambridge, and Newmarket General Hospital, and the Department of Community Medicine, Fenners, Gresham Road, Cambridge

SUMMARY Three hundred and eleven patients with classical or definite rheumatoid arthritis were observed over an 11-year period. This group is of particular interest since 214 patients were given cytotoxic therapy, 203 were treated with azathioprine (52 of these also received chlorambucil or cyclophosphamide), and 11 were treated with cyclophosphamide or chlorambucil alone. Forty-six patients died. This is an excess mortality compared with the expected rate for the general population matched with respect to age and sex. The death rate was higher than expected in the age group 45-64 years but lower in those aged 75 years or over. There were more deaths from neoplasia and ischaemic heart disease in the younger age group. One patient died of lymphosarcoma; treatment had been with corticosteroids, gold, and chloroquine. No other tumours of the reticuloendothelial system were recorded, and no patient developed leukaemia.

Several controlled studies have demonstrated suppression of disease activity in rheumatoid arthritis by azathioprine. ${ }^{1-3}$ Since this treatment does not produce a lasting remission, long-term administration would be expected in many instances. This focuses attention on the adverse effects of prolonged administration of azathioprine, including bone marrow suppression, susceptibility to infection, and the potential development of malignant tumours.

The cause of death in patients with rheumatoid arthritis has been assessed both by surveys based on clinical populations and by reviews of necropsy records. ${ }^{4-11}$ There have been few attempts to assess the influence of drug therapy on mortality or the incidence of neoplasia.

The patients in this study are unusual in that treatment with azathioprine was commenced in some patients as long as 11 years ago, often in high dosage, $5 \mathrm{mg} \mathrm{kg} /$ day, and sodium aurothiomalate has been given in combination.

In view of the observed increased frequency of lymphoreticular neoplasm arising in recipients treated transiently with immunosuppressive drugs ${ }^{12} 13$ this study has set out to assess the incidence of the type of tumour and other neoplasms in a closely surveyed group of rheumatoid patients.

For purposes of comparison an analysis of

Accepted for publication 11 October 1979.

Correspondence to Dr B. L. Hazleman, Addenbrooke's Hospital, Hills Road, Cambridge CB2 2QQ. mortality was performed by calculation of expected mortality in the patient group based on rates for a sample of similar age and sex distribution from the general population.

\section{Patients and methods}

Three hundred and eleven patients with classical or definite rheumatoid arthritis attended the rheumatology clinics at Newmarket General Hospital and the West Suffolk Hospital over an 11-year period (1966-76). Hospital records of all patients were reviewed for evidence of neoplasia; associated pathology and the drug therapy were recorded. In addition 137 of these patients currently attending hospital received a detailed clinical examination. Investigations included: Haemoglobin, leucocyte count, and erythrocyte sedimentation rate; plasma proteins, bilirubin, transaminase; blood urea; urine analysis and microscopy; chest radiograph.

Patients discharged from the clinic were contacted through their general practitioners. Follow-up was complete in all patients. The death certificate was obtained for all the deceased, and results of necropsy were available in 19 cases.

\section{Results}

DR UG THERAPY

Many patients in this study were initially referred 
with active disease requiring treatment with corticosteroids. Gold was used in an attempt to wean patients off corticosteroids and azathioprine was added in the hope that gold toxicity might be reduced. The outcome of this unique combination therapy will be reviewed elsewhere. However, most patients previously receiving corticosteroids $(26 \%)$ could be weaned off this drug.

Azathioprine was given to a maximum dose of $5 \mathrm{mg} / \mathrm{kg}$ body weight/day for 5-6 days a week. Therapy was often intermittent and dependent on disease activity. In all, 214 patients received cytotoxic therapy for a mean duration of $2 \cdot 5$ years (range 1-11 years); 500 patient years of treatment with azathioprine were observed. Of these 214 patients 63 received cyclophosphamide (range $0 \cdot 2$ 8 years) or chlorambucil at some stage in their disease.

\section{MORTALITY ANALYSIS}

Calculations of death rate require knowledge of sex, date of birth, and date of referral to the clinic or date of death. Expected mortality in the group was calculated from numbers at risk in each sex and age group for each year of follow-up. Death rates for persons dying of all diseases ICD (000-796) and age-related specific causes in the general population of England and Wales over the period of study were used to calculate expected values in the rheumatoid population. These were obtained from the Registrar-General's Statistical Review of England and Wales for 1973.

The tumours diagnosed in both the deceased and the survivors is recorded in Table 1. Five patients have had apparently successful treatment of their neoplasm ( 3 patients had received cytotoxic therapy before the discovery of the neoplasia). Ten of the 20 neoplasms were in patients who were receiving cytotoxic therapy (Table 2). There is no reason to link rheumatoid arthritis with any particular form of tumour.

Table 1 Types of neoplasias

\begin{tabular}{ll}
\hline $\begin{array}{l}\text { Rheumatoid arthritis } \\
\text { Neoplasia }\end{array}$ & $1966-76$ \\
\hline Lung/bronchus & 5 \\
Breast & 4 \\
Prostate & 2 \\
Uterus & 1 \\
Rectum & 1 \\
Colon & 1 \\
Bowel unspecified & 1 \\
Thyroid (anaplastic) & 1 \\
Multiple bladder neoplasia & 1 \\
Unspecified & 1 \\
Lymphosarcoma & 1 \\
Basal cell carcinoma of skin & 1 \\
Total & 20 \\
\hline
\end{tabular}

Table 2 Neoplasia in cytotoxic group

\begin{tabular}{|c|c|c|}
\hline $\begin{array}{l}\text { Carcinomas, deceased } \\
\text { patients }\end{array}$ & Therapy & $\begin{array}{l}\text { Duration } \\
\text { (years) }\end{array}$ \\
\hline Lung/bronchus & $\left\{\begin{array}{l}\text { Cyclophosphamide } \\
\text { Azathioprine }\end{array}\right.$ & $\begin{array}{l}2 \cdot 3 \\
0 \cdot 3\end{array}$ \\
\hline Lung/bronchus & Azathioprine & 5 \\
\hline Lung/bronchus & $\begin{array}{l}\text { Chlorambucil } \\
\text { Azathioprine }\end{array}$ & $\begin{array}{l}1 \cdot 7 \\
3\end{array}$ \\
\hline Breast & $\begin{array}{l}\text { Intra-articular } \\
\text { Cyclophosphamide }\end{array}$ & \\
\hline $\begin{array}{l}\text { Rectum } \\
\text { Unspecified }\end{array}$ & $\begin{array}{l}\text { Azathioprine } \\
\text { Azathioprine }\end{array}$ & $\begin{array}{l}2 \\
1 \cdot 5\end{array}$ \\
\hline Carcinomas prevalent & & \\
\hline Uterus & Azathioprine & 8 \\
\hline $\begin{array}{l}\text { Thyroid } \\
\text { Multiple bladder }\end{array}$ & Azathioprine & 3 \\
\hline $\begin{array}{l}\text { neoplasm } \\
\text { Basal cell carcinoma }\end{array}$ & $\begin{array}{l}\text { Cyclophosphamide } \\
\text { Azathioprine }\end{array}$ & $\begin{array}{l}8 \\
5\end{array}$ \\
\hline
\end{tabular}

Table 3 Principal causes of death in the 46 patients

\begin{tabular}{lcl}
\hline Rheumatoid arthritis & Mortality & 46 patients \\
\hline Cardiovascular: & 15 & $(7)^{*}$ \\
Ischaemic heart disease & 2 & $(1)$ \\
Cor pulmonale & 2 & $(1)$ \\
Pulmonary embolus & 13 & $(2)$ \\
Neoplasia & 6 & $(3)$ \\
Respiratory infections & 3 & $(2)$ \\
Chronic pulmonary disease & 2 & $(2)$ \\
Others & 1 & $(1)$ \\
$\quad$ Adrenal failure & 1 & \\
Cirrhosis, portal hypertension & 1 & \\
Peptic ulceration & & \\
Cervical subluxation & & \\
\hline
\end{tabular}

*Number in parentheses indicates confirmed at necropsy.

Table 4 Comparison of the observed death rate with expected values obtained from the Registrar-General's Office

\begin{tabular}{llll}
\hline Rheumatoid arthritis & Mortality & 1966-7 311 patients \\
\hline Age in years & $\begin{array}{l}\text { Patient years } \\
\text { at risk }\end{array}$ & Mortality \\
\cline { 2 - 4 } & & Expected & Observed \\
\hline $25-44$ & 270 & $0 \cdot 2$ & 1 \\
$45-64$ & 1185 & $10 \cdot 2$ & 23 \\
$65-74$ & 506 & $18 \cdot 3$ & 17 \\
75 & 95 & $11 \cdot 9$ & 5 \\
Total & 2056 & $40 \cdot 8$ & 46 \\
\hline
\end{tabular}

$\chi^{2}=22 \cdot 27 . \mathrm{P}<0 \cdot 0005$.

The 1 case of lymphosarcoma occurred in a 71-year-old patient with no evidence of Sjögren's syndrome who had not received cytotoxic therapy.

Principal causes of death are listed (Table 3). Ischaemic heart disease heads the list followed by neoplasia. Deaths due to infections all involved the lung, and the incidence is lower than previously recorded in patients with rheumatoid arthritis. ${ }^{714}$

The observed death rate from all causes according to age has been compared by the chi-square test 
Table 5 Rheumatoid arthritis mortality 1966-76

\begin{tabular}{|c|c|c|c|c|c|c|}
\hline & \multicolumn{2}{|c|}{ All diseases } & \multicolumn{2}{|c|}{ All malignant neoplasms } & \multicolumn{2}{|c|}{ Ischaemic heart disease } \\
\hline & Observed & Expected & Observed & Expected & Observed & Expected \\
\hline $\begin{array}{l}1966-70 \\
1971-72 \\
1973-74 \\
1975-76 \\
\text { Total }\end{array}$ & $\begin{array}{l}10 \\
11 \\
15 \\
10 \\
46\end{array}$ & $\begin{array}{r}7 \cdot 2 \\
7 \cdot 4 \\
11 \cdot 6 \\
14 \cdot 5 \\
40 \cdot 7\end{array}$ & $\begin{array}{r}2 \\
4 \\
4 \\
3 \\
13\end{array}$ & $\begin{array}{l}1 \cdot 7 \\
1 \cdot 9 \\
2 \cdot 6 \\
3 \cdot 1 \\
9 \cdot 3\end{array}$ & $\begin{array}{r}6 \\
4 \\
3 \\
2 \\
15\end{array}$ & $\begin{array}{r}1 \cdot 8 \\
2 \cdot 0 \\
3 \cdot 0 \\
3 \cdot 7 \\
10 \cdot 5\end{array}$ \\
\hline
\end{tabular}

with expected values obtained from the RegistrarGeneral's records. The difference is significant, $P<0 \cdot 0005$. The death rate was higher than expected in the 45-64 year old age group but lower in those aged 75 years or over (Table 4). There is good agreement, however, between observed and expected values for each chosen interval of follow-up (Table 5).

The observed and expected deaths during the years of the study are shown. There is a progressive decline in patients dying of ischaemic heart disease at each interval of follow-up but the number of cases in this analysis is insufficient to allow statistical evaluation. There is no change in the number of deaths from malignancy.

Analysis of age-related specific causes of death (Table 6) showed an increased frequency of deaths due to neoplasia and ischaemic heart disease occurring in the 45-64 year old age group, but this is not significant.

\section{Discussion}

Most surveys of the causes of death in rheumatoid arthritis agree that patients with the disease have a higher mortality rate than the rest of the population, though they die not so much from specific complications of the disease as from all the usual causes of death at an earlier age than usual.

In 1970 Uddin et al. ${ }^{8}$ reviewed 475 patients with rheumatoid arthritis, first seen between 1954 and 1966. The cumulative survival rate was determined in each year for up to 10 years, compared with that of a normal matched population. This was lower than expected for each sex at each year of follow-up, particularly in the later years.

Table 6 Rheumatoid arthritis: mortality by age-related specific causes, 1966-76

\begin{tabular}{llllll}
\hline Age in years & \multicolumn{2}{l}{ Neoplasia } & & \multicolumn{2}{l}{ Ischaemic heart disease } \\
\cline { 2 - 3 } \cline { 5 - 6 } & Observed & Expected & & Observed & Expected \\
\hline $25-45$ & - & $0 \cdot 11$ & & - & $0 \cdot 320$ \\
$45-64$ & 6 & $3 \cdot 3$ & & 10 & $2 \cdot 626$ \\
$65-74$ & 5 & $4 \cdot 6$ & & 5 & $5 \cdot 117$ \\
75 & 2 & $1 \cdot 2$ & & -13 & $2 \cdot 521$ \\
Total & 13 & 9.4 & 13 & $10 \cdot 584$ \\
\hline
\end{tabular}

Cobb et al. ${ }^{4}$ followed up 583 patients for a mean duration of $9 \frac{1}{2}$ years. The overall mortality rate was 24.4 per 1000 patients per year in contrast to 18.9 for a comparable group matched for age and sex. More recently Isomaki et al. ${ }^{10}$ observed 1000 patients with rheumatoid arthritis for 3 years. All were over 40 years of age. Deaths were compared with an age and sex matched control population. Their 122 deaths in the rheumatoid group compared with 69 in the controls.

It is difficult to compare studies in the causes of death in rheumatoid patients, Most studies rely on certified causes of death, which on occasion do not correlate well with findings at necropsy. The improved hospital supervision of rheumatoid patients and the use of an expanded range of therapeutic agents in the last decade may invalidate comparisons with early studies.

Our findings of an increased frequency of deaths due to cardiovascular disease in rheumatoid arthritis agree with the recent study of Isomaki et al., ${ }^{10}$ who used a control population for purposes of comparison. Earlier studies show myocardial infarction to be less common in rheumatoid arthritis than in the general population, ${ }^{8}$ and Ball $^{5}$ states that it is usually secondary to atherosclerosis.

It is noticeable that while infections feature as a common cause of death in earlier studies ${ }^{8}$ recent reports show a decline since the advent of antibiotics. In contrast, Gordon et al. ${ }^{15}$ found that after 5 years $20 \%$ of their rheumatoid patients inad died, almost half of them from infection. The mortality was twice as high in those with extra-articular lesions as in those without, and was even higher in patients with more than 1 extra-articular feature.

Reports of neoplasia vary between studies. Only Moesmann $^{6}$ found a greater frequency of malignant disease in a small group of elderly patients. It is of interest that the incidence of malignant disease in the present study is higher than expected, particularly in view of the widespread use of immunosuppressive therapy in this group of patients.

Four cases of leukaemia have arisen in association with rheumatoid arthritis following treatment with azathioprine ${ }^{16-18}$ and in 2 cases following 
treatment with cyclophosphamide. ${ }^{17}$ Parsons et al. ${ }^{19}$ carried out a long-term follow-up of patients with rheumatoid arthritis treated with cyclophosphamide; they found 8 malignancies, including 7 of the lymphoproliferative variety. Pollock et al. ${ }^{20}$ reported 2 malignancies in rheumatoid arthritis patients treated with cyclophosphamide (both solid tumours), and a recurrence of a previously treated melanoma was reported in a patient following cyclophosphamide therapy. ${ }^{21}$

In view of these findings Hunter et al. ${ }^{22}$ carried out chromosomal studies in patients on long-term azathioprine. This showed a 2-fold increase in chromosomal abnormalities in patients, like that reported for cyclophosphamide in rheumatoid arthritis. ${ }^{23}$ Since similar changes may occur with phenylbutazone and a variety of other drugs, its significance will have to await long-term observation.

Evidence is accumulating to suggest that lymphoreticular tumours may be associated with autoimmune disease. ${ }^{24-27}$ Patients with Sjögren's syndrome are especially prone to develop extensive lymphocyte infiltrates in extrasalivary organs with pseudolymphoma formation and occasional progression to malignant lymphoma. ${ }^{27}$

An increased incidence of malignant neoplasm has been reported in transplant recipients in whom neoplasia was incidental to the transplant procedure. ${ }^{13}$ Neoplastic lesions of the skin are the most commonly encountered tumours in these patients. ${ }^{28}$ However, neoplasms of lymphoreticular origin are reported to arise far more frequently than expected and to occur in atypical sites, ${ }^{29}$ though factors other than immunosuppressive therapy may be involved to account for this increase. ${ }^{30}$

One patient developed a transitional cell carcinoma of the bladder after 8 years' therapy with cyclophosphamide. This is of interest, as Wall and Clausen $^{31}$ described 5 cases of carcinoma of the bladder following prolonged cyclophosphamide therapy. In each case interstitial haemorrhagic cystitis preceded the development of the carcinoma. The patients all developed fatal and invasive carcinomas. Dale and $\mathrm{Smith}^{32}$ suggested that the tumour could be small and possibly nonrecurrent. The patient in this study has had local recurrences which have been removed at routine cystoscopy.

The presence of haemorrhagic cystitis in a patient receiving cyclophosphamide should suggest immediate and permanent discontinuation of the drug. However, the cessation of haematuria and withdrawal does not eliminate the need for cystoscopy, and perhaps this should be carried out periodically thereafter. Previous observations have shown atypical epithelial cells on cytology in haemorrhagic cystitis after cyclophosphamide, ${ }^{33}$ and a necropsy study showed that 10 of 49 patients who had received long-term cyclophosphamide had signs of urinary bladder fibrosis, the frequency being related to dose and duration of therapy. In about $50 \%$ of cases the fibrosis did not produce symptoms.

These findings suggest caution in the use of cyclophosphamide for nonmalignant conditions. It is suggested protracted periods of treatment should be avoided and that the drug be used in intermittent courses if at all possible,

Isomaki et al. ${ }^{10}$ in Finland found that fewer rheumatoid patients die from cancer than from other disease. While there were more deaths from neoplasia in this study, it should be noted that they were not more common in patients receiving azathioprine. The potential oncogenic effect of azathioprine remains one of the main deterrents to its widespread use in the treatment of rheumatoid arthritis. Further follow-up of this group of patients should help to assess the influence of this drug on the incidence of tumours in rheumatoid arthritis.

We thank Dr R. Arden Jones for his encouragement to study his patients and Professor R. Acheson for his advice, in whose department much of this work was carried out. WeO also thank Mrs J. Fowle for the typing of the manuscripts.

We thank the Arthritis and Rheumatism Council fore continuing support.

\section{References}

1 Mason M, Currey H L F, Barnes C G, Dunne J F, Hazleman B L, Strickland I D. Azathioprine in rheumatoid arthritis. Br Med $J$ 1969; 1 : 420-2.

2 Gordon D A, Smythe H A, Pruzanski M A, Ogryzio M A. Azathioprine in rheumatoid arthritis. A doubleblind cross-over study. Arthritis Rheum 1973; 16: 411-8.

3 Currey H L F, Harris J, Mason R M, et al. Comparison of azathioprine, cyclophosphamide and gold in treatment of rheumatoid arthritis. $\mathrm{Br} \mathrm{Med} J \mathrm{~J}$ 1974; 3: 763-6.

4 Cobb S, Anderson F, Bauer W. Length of life and cause of death in rheumatoid arthritis. N Engl J Med 1953; 249: 553-6.

5 Ball J. Postmortem findings and articular pathology in rheumatoid arthritis. In: Duthie $\mathbf{J} \mathbf{J} \mathbf{R}$, Alexander W R M, eds. Rheumatic Diseases: Pfizer Medical Monograph. Edinburgh: University Press, 1968; 3: 124-6.

- Moesmann G. Malignancy and mortality in subacute rheumatoid arthritis in old age. Acta Rheumatol Scand 1969; 15: 193-9.

7 Owen D S Jnr, Waller M, Toone E C Jnr. Rheumatoid arthritis and malignancy. Med Coll Virginia $Q$ 1970; 6: 8-10.

8 Uddin J, Kraus A S, Kelly H G. Survivorship and death in rheumatoid arthritis. Arthritis Rheum 1970; 13: 12531 .

9 Gardner D L. Causes of death. The Pathology of Rheumatoid Arthritis. London: Arnold, 1972: 183-7.

10 Isomaki $\mathrm{H} A$, Mutru O, Koota $\mathrm{K}$. Death rate and causes of death in patients with rheumatoid arthritis. Scand $J$ Rheumatol 1975; 4: 205-8.

11 Mutru O, Koota K, Isomaki H. Causes of death in autopsied R.A. patients. Scand J Rheumatol 1976; 5: 239-40. 
12 Schneck S, Penn I. De-novo brain tumours in renaltransplant recipients. Lancet 1971 ; 1 : 983-6.

13 Penn I. The incidence of malignancies in transplant recipients. Transplant Proc 1975; 7: 323-6.

14 Bywaters E, Curwen M, Dresner E, Dixon A St J. 10 year follow-up study of rheumatoid arthritis. Ann Rheum Dis 1961; 20: 198.

15 Gordon D A, Stein J L, Broder I. The extra articular features of rheumatoid arthritis. A systemic analysis of 127 cases. Am J Med 1973; 54: 445-52.

16 Cobau C D, Sheon R P, Kirsner A B. Immunosuppressive drugs and acute leukemia. Ann Intern Med 1973; 79: 1312.

17 Love R R, Sowa J M. Myelomonocytic leukaemia following cyclophosphamide therapy of rheumatoid disease. Ann Rheum Dis 1975; 34: 534-5.

18 Seidenfeld A M, Smythe H A, Ogryzio M A, Urowitz M B, Dotton D A. Acute leukaemia in rheumatoid arthritis treated with cytotoxic agents. $J$ Rheumatol 1976; 3: 295-304.

19 Parsons J L, Strong J S, Fosdick W M. The causes of death in patients with rheumatoid arthritis treated with cytotoxic agents. $J$ Rheumatol Suppl. 1 1974; 1 : 75.

20 Pollock B H, Barr J H, Stolzer B L. Neoplasia and cyclophosphamide. Arthritis Rheum 1973: 16: 524

21 McCracken J D. Additional risk from immunosuppressive therapy for rheumatoid arthritis. Ann Intern Med 1973; 79: 611-2.

22 Hunter T, Urowitz M B, Gordon D A, Smythe H A, Ogryzio M A. Azathioprine in rheumatoid arthritis: a long-term follow-up study. Arthritis Rheum 1975; 18: 15-20.
23 Tolchin S F, Winkelstein A, Rodnan G P, Pan S F, Nankin H R. Chromosome abnormalities from cyclophosphamide therapy in rheumatoid arthritis and progressive systemic sclerosis (scleroderma). Arthritis Rheum 1974; 17: 375-82.

24 Cammarata R J, Rodnan G P, Jenson W N. Systemic rheumatic disease and maligant lymphoma. Arch Intern Med 1963; 3: 330-7.

25 Talal N, Bunim J J. The development of malignant lymphomata in the course of Sjögren's syndrome. Am J Med 1964; 36: 529-40.

26 Miller D G. The association of immune disease and malignant lymphoma. Ann Intern Med 1967; 66: 507-21.

27 Anderson L G, Talal N. The spectrum of benign to malignant lymphoproliferation in Sjögren's syndrome. Clin Exp Immunol 1972; 10: 199-221.

28 Walder B K, Robertson M R, Jeremy D. Skin cancer and immunosuppression. Lancet 1971; 2: 1282-3.

29 Doll R, Kinlen L. Immunosurveillance and cancer: epidemiological evidence. $\mathrm{Br}$ Med J 1970; 4: 420-2.

30 Schwartz R S. Immunoregulation oncogenic viruses, and malignant lymphomas. Lancet 1972; 1 : 1266-9.

31 Wall R L, Clausen K P. Carcinoma of the urinary bladder in patients receiving cyclophosphamide. $N$ Engl $J$ Med 1975; 293: 271-3.

32 Dale G A, Smith R B. Transitional cell carcinoma of the bladder associated with cyclophosphamide. J Urol 1974; 112: 603-4.

33 Forni A M, Koss L G, Geller W. Cytological study of the effect of cyclophosphamide on the epithelium of the urinary bladder in man. Cancer 1964; 17: 1348-55. 